\title{
FACTORS THAT INFLUENCE COVERAGE DEGREE IN SEED TREATMENT EQUIPMENT HAVING BRUSH SCREW CONVEYOR
}

\author{
Alexandru Zaica, Mihai Olan, George Bunduchi, Ana Zaica, Paul Gageanu, Anisoara Paun \\ National Institute of Research-Development for Machines and Installations \\ Designed to Agriculture and Food Industry, Romania \\ zaica_alexandru@yahoo.com
}

\begin{abstract}
In order to obtain optimum harvests, seed treatment must ensure disease and pest control, germination stimulation and plantlet emergence, healthy roots forming and the emergence of a uniform and thick culture that preserves the integrity of the seed genetic potential. Chemicals currently have a basic role in plant protection and in the future they will play an important role; with the aim of reducing the dose, increasing the selectivity, reducing and controlling the persistence, a permanent action is being required, as changes are constantly occurring in the evolution of harmful organisms, resistant types appear, etc., it is necessary that the assortment of pesticide products contain less and less toxic products. The paper presents experimental research results conducted on equipment with brush screw conveyor, which allowed variation of operating parameters that are then graphically represented. The testing methodology for treatment equipment has been developed according to the construction features and functional parameters. Therefore, we determine the interdependence between the coverage degree and some functional parameters that were measured and can formulate recommendations for the use of these types of equipment. This paper is a continuation and completion of the paper "Coating process of corn grains using treatment machine with brush screw conveyor" last year publication in proceedings of "Engineering for Rural Development", which will emphasize the interdependence of the main parameters involved in the treatment process.
\end{abstract}

Keywords: corn; coating process; screw conveyor equipment.

\section{Introduction}

The corn coating technology is mainly focused on developing uniform and accurate application of specific substances, and often new and innovative, on the surface of corn. The application of active ingredients as a corn coating is precise and eliminates the old need for spraying products over entire fields. A coating seed establishes uniform seeding and can include certain types of substances, such as pesticides, and other amendments required in general at planting [1]. The benefits of cropping of coating corns in both conventionally and organic managed systems are well documented [2]. Cover crops increase soil structure, soil organic matter, nutrient retention, and reduce soil erosion [3]. Still, under drought conditions, and in areas with poor soils and arid degraded grasslands, the germination and subsequent growth of cover crops are inadequate, and sowing is often unsuccessful. Actually the modern grain coating technology allows the delivery of some types of materials that can improve the plant growth and enlarge seedling stand establishment at remissive application rates compared to the foliar or soil applied methods $[4 ; 5]$. The technology needs to be convenient and safe for growers, to have minimal impact on the environment, and active ingredients should be applied at the lowest possible dose rate. These safety requirements are driving the development of improved formulations in grain enhancement technologies [6; 7]. Grain enhancements, which can include grain priming, coating, and conditioning, are frequently used to improve grain delivery during planting, and to increase grain germination, seedling growth, stand uniformity, and suppress diseases [8]. Grain invigoration is a range of treatments of grains that improves their performance after harvesting and conditioned, but before they are sown. They are used to improve grain sowing, germination and seedling growth by altering grain vigor and/or the physiological state of the grains. The alteration may improve vigor or the physiological state of the seed and finally improve the yield potential by enhancing uniformity of germination, and healthy seedling [9].

\section{Materials and methods}

The structure of the experimental stand is composed of: frame 1; the feed hopper 2 provided at the bottom with a pawl that ensures uniform flow of seeds; spraying drum 3, inside which the spreader disk is mounted; liquid dispenser 4; homogenizing conveyor 5; liquid tank 6 and the power and control electrical installation 7, Fig.3.2. 


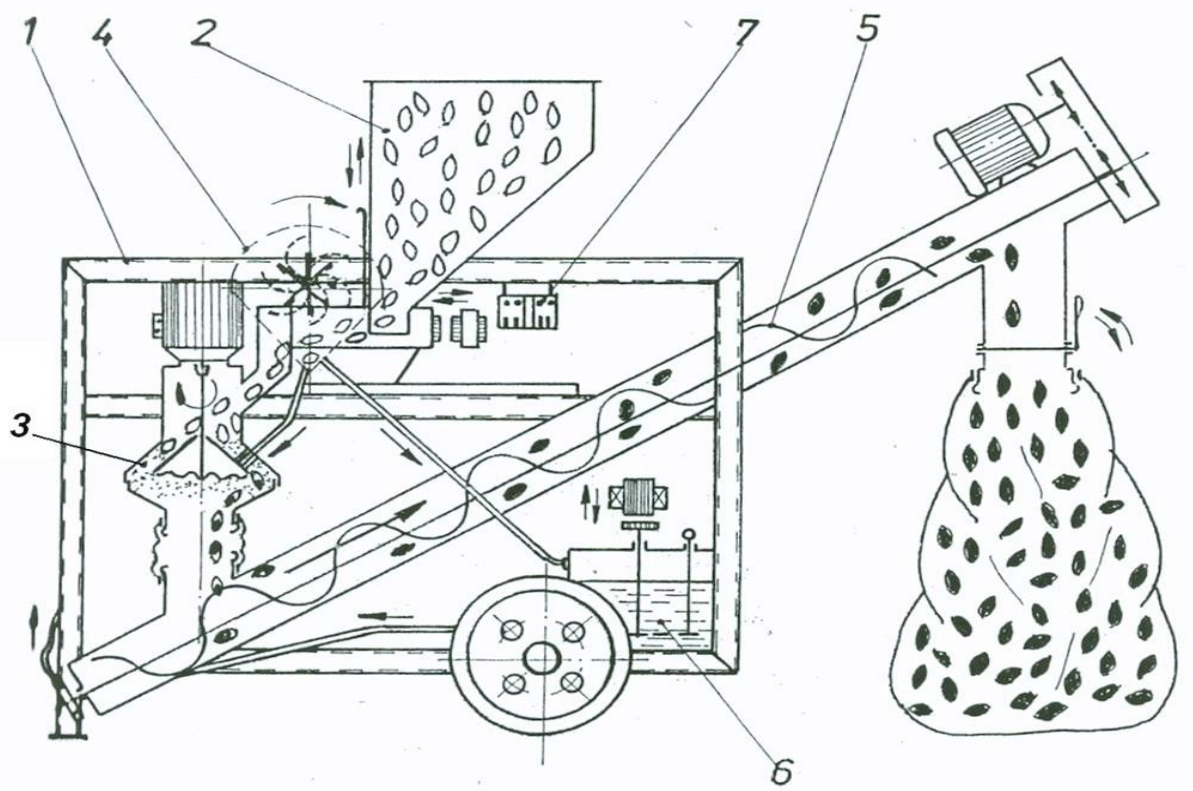

Fig. 1. Seed sample taken at the exit of the disc drum

The research and the experimental activities were performed using a machine that was designed and produced at INMA Bucharest using the same methodology and the same raw material [10]

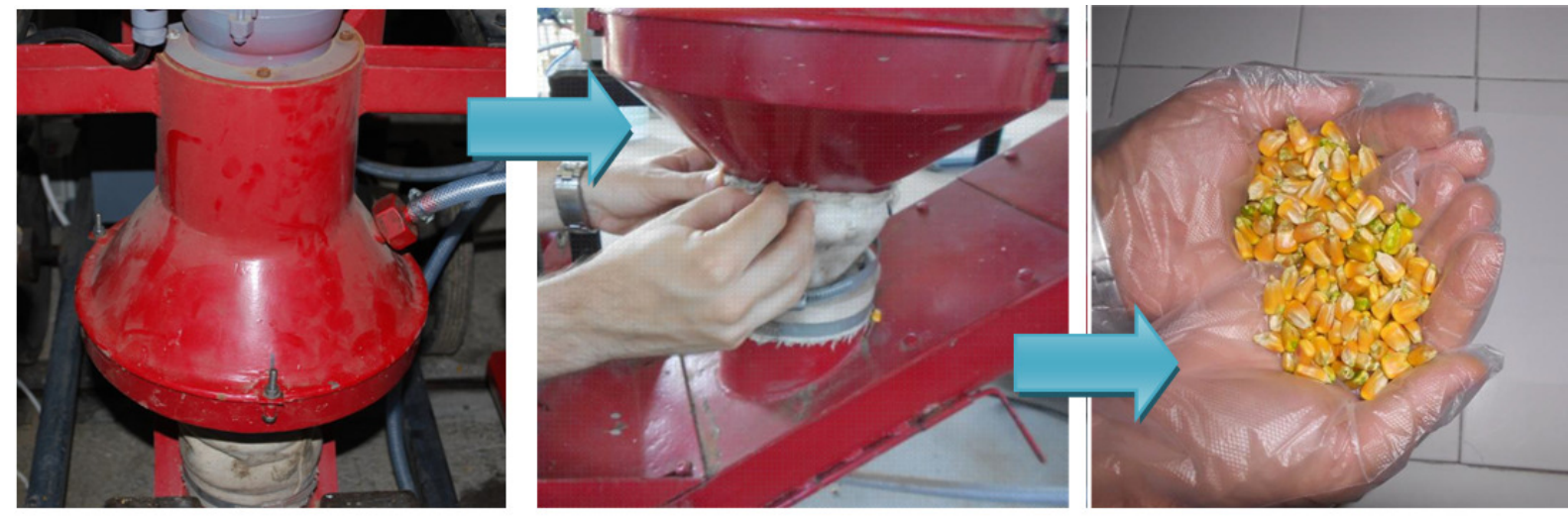

Fig. 2. Seed sample taken at the exit of the disc drum

Drum with sprayer - inside it the spreading disk is mounted, coupled to an electric motor that ensures a speed of $3000 \mathrm{rpm}$; ensures spraying of the liquid to be treated on the seed surface (Fig. 2).

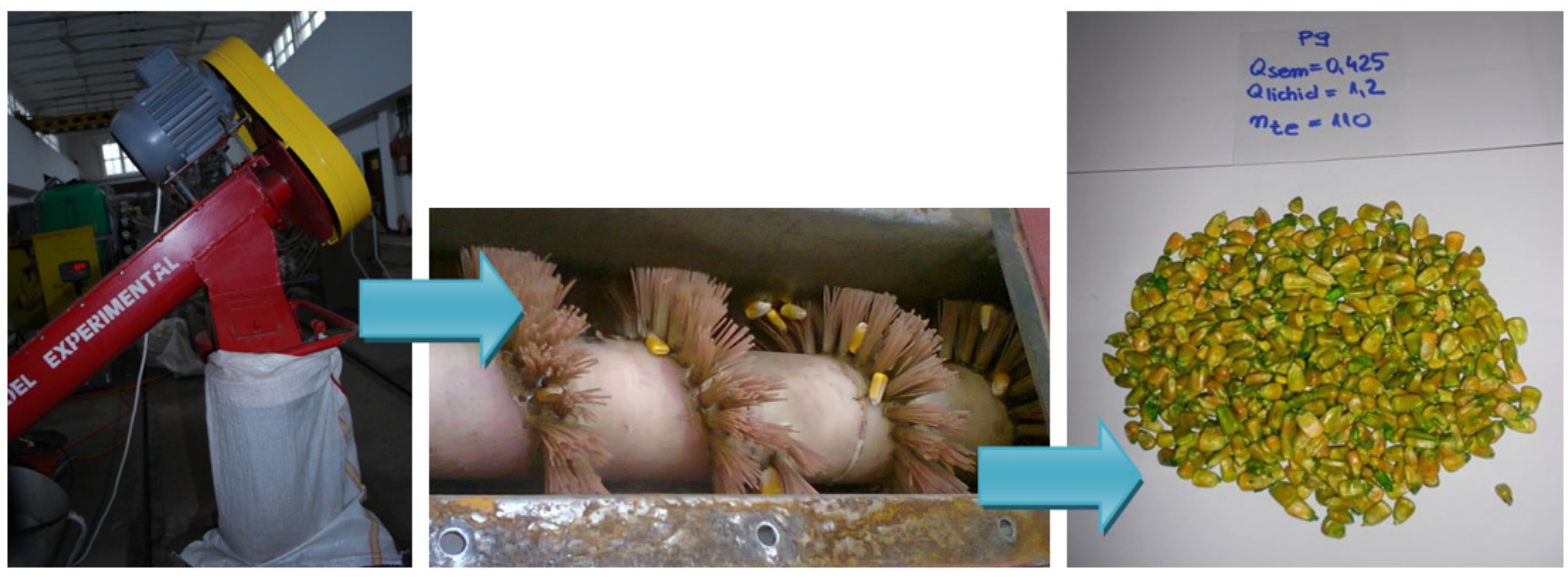

Fig. 3. Seed sample taken at the exit of the helical conveyor 
Homogenizing conveyor - is a subassembly that includes: trough - welded metal construction, provided with two holes for the product evacuation bag, a conveyor with brushes of relon yarn, a pump that transports the liquid from the tank to the liquid dispenser, brushes of the conveyor have the role of transporting the product to the mouths of the bag, but at the same time they achieve homogeneous wetting with the liquid to be treated (Fig. 3).

\section{Results and discussion}

For a more thorough investigation of the degree of coverage, we divided the experimental stand into three distinct parts in order to obtain three degrees of coverage of the respective seeds:

- Gac 1 - the degree of coverage at the exit of the drum with a trunk disk (Fig. 2);

- Gac 2 - the degree of coverage at the exit of the helical conveyor (without being operated the disc drum) (Fig. 3); Gac final - the degree of final coverage, in which the seeds pass through both the trunk disk drum and the helical conveyor.

Applying the general conditions from the polytopic function,calculation of coefficients, and following the data obtained in the experimental researches using the specific regulations, we applied for each degree of coverage the structure of a factorial program divided by tests for three independent variables [11-14].

Structure of the test program for determination of $\mathbf{G}$ ac 1 and $\mathbf{G}$ ac 2

Table 1

\begin{tabular}{|c|c|c|c|c|c|}
\hline \multirow{2}{*}{$\boldsymbol{Q}_{\boldsymbol{s}}, \mathbf{~ k g} \cdot \mathbf{s}^{-\mathbf{1}}$} & \multirow{2}{*}{$\boldsymbol{Q}_{l}, \mathbf{l} \cdot \mathbf{m i n}^{-\mathbf{1}}$} & \multicolumn{2}{|c|}{ Coverage degree 1 (Gac 1) } & \multicolumn{2}{c|}{ Coverage degree 2 (Gac 2) } \\
\cline { 3 - 6 } & & $\boldsymbol{n}_{\boldsymbol{d t c}}, \mathbf{r p m}$ & $\boldsymbol{G}_{\boldsymbol{a c}} \mathbf{1} \mathbf{\%} \boldsymbol{\%}$ & $\boldsymbol{n}_{\boldsymbol{t}}, \mathbf{r p m}$ & $\boldsymbol{G}_{\boldsymbol{a c}} \mathbf{2 , \boldsymbol { \% }}$ \\
\hline 0.287 & 0.36 & 2000 & 32.4 & 110 & 59.6 \\
\hline 0.425 & 0.36 & 2000 & 23.8 & 110 & 50.8 \\
\hline 0.287 & 1.20 & 2000 & 34.6 & 110 & 60.4 \\
\hline 0.425 & 1.20 & 2000 & 26.8 & 110 & 54.0 \\
\hline 0.287 & 0.36 & 3000 & 38.2 & 282 & 64.2 \\
\hline 0.425 & 0.36 & 3000 & 28.2 & 282 & 58.2 \\
\hline 0.287 & 1.20 & 3000 & 46.4 & 282 & 65.6 \\
\hline 0.425 & 1.20 & 3000 & 29.8 & 282 & 60.6 \\
\hline 0.287 & 0.65 & 2500 & 40.8 & 190 & 61.8 \\
\hline 0.425 & 0.65 & 2500 & 27.8 & 190 & 58.4 \\
\hline 0.342 & 1.20 & 2500 & 36,8 & 190 & 60.4 \\
\hline 0.342 & 0.36 & 2500 & 33.2 & 190 & 59.0 \\
\hline 0.342 & 0.65 & 3000 & 37.8 & 282 & 62.2 \\
\hline 0.342 & 0.65 & 2000 & 28.8 & 110 & 56.0 \\
\hline 0.342 & 0.65 & 2500 & 34.6 & 190 & 60.2 \\
\hline 0.342 & 0.65 & 2500 & 34.9 & 190 & 64.0 \\
\hline 0.342 & 0.65 & 2500 & 38.0 & 190 & 58.0 \\
\hline 0.342 & 0.65 & 2500 & 36.0 & 190 & 62.0 \\
\hline
\end{tabular}

Following the compilation of the experimental data and of their use of mathcad we obtained the following variations of the degrees of coverage according to the flow of liquid (the substance of coverage) both for the coverage at the exit of the drum as well as for the coverage at the exit of the conveyor (Fig. 4 to Fig. 9).

These variations give the possibility to have a vision on the variations produced during usage and to be able to set the equipment to an optimal regime.It is also noticed that a simple aspersion in the disc drum is not sufficient, the coverage degree of the corn grains being very small and that it is necessary to pass it through the inclined conveyor with brushes. 


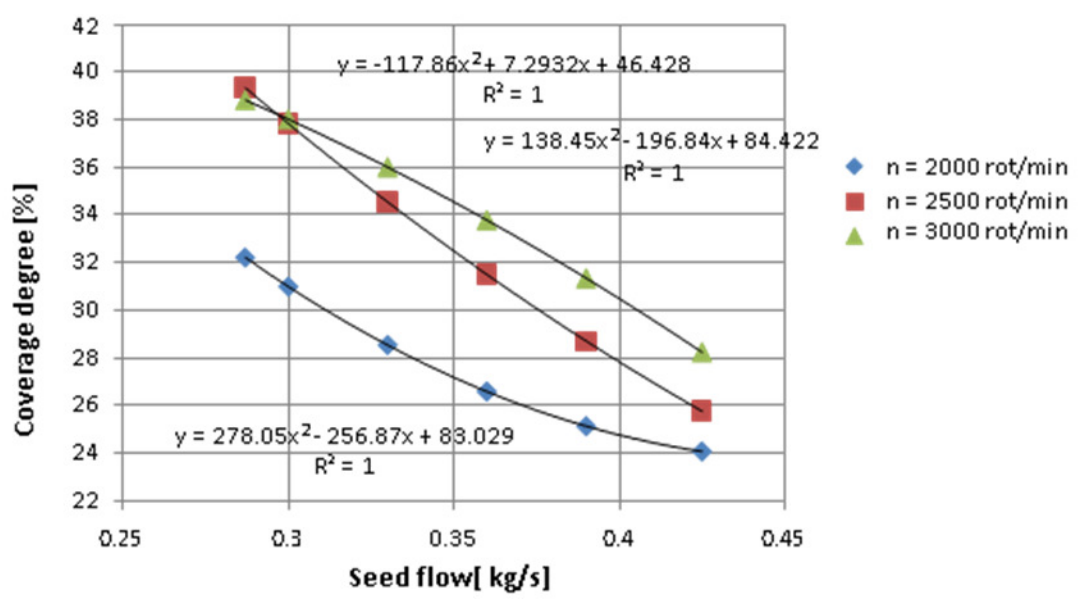

Fig. 4. Variation of the coverage degree according to the seed flow for the liquid flow $Q_{l}=0.36 \mathrm{l} \cdot \mathrm{min}^{-1}$

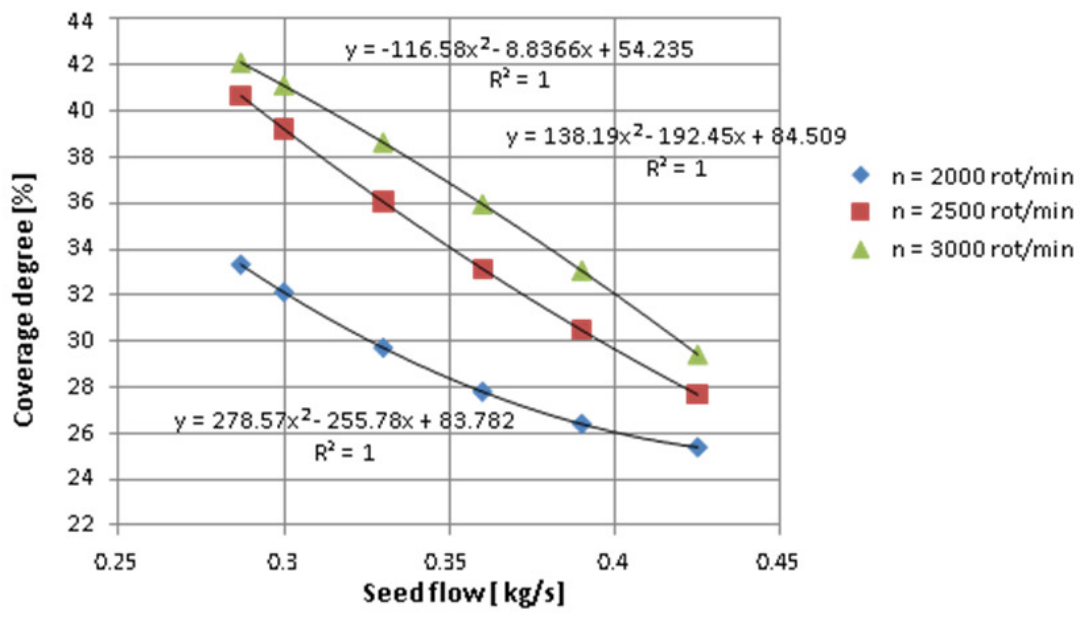

Fig. 5. Variation of the coverage degree according to the seed flow for the liquid flow $Q_{l}=0.65 \mathrm{l} \cdot \mathrm{min}^{-1}$

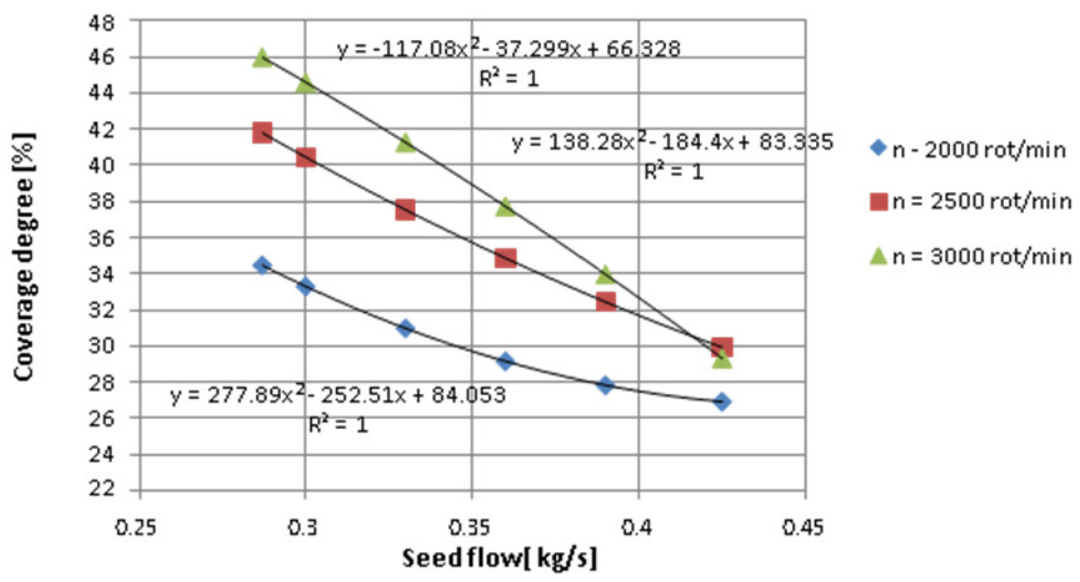

Fig. 6. Variation of the coverage degree according to the seed flow for the liquid flow $Q_{l}=1.21 \mathrm{l} \cdot \mathrm{min}^{-1}$ 


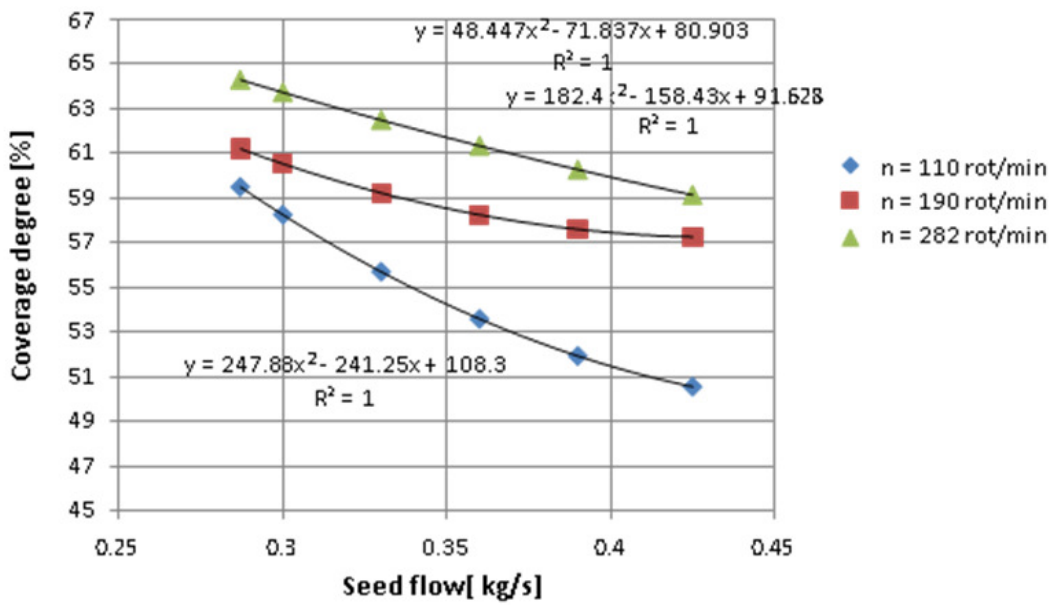

Fig 7. Variation of the coverage degree according to the seed flow for the liquid flow $Q_{l}=0.36 \mathrm{l} \cdot \mathrm{min}^{-1}$

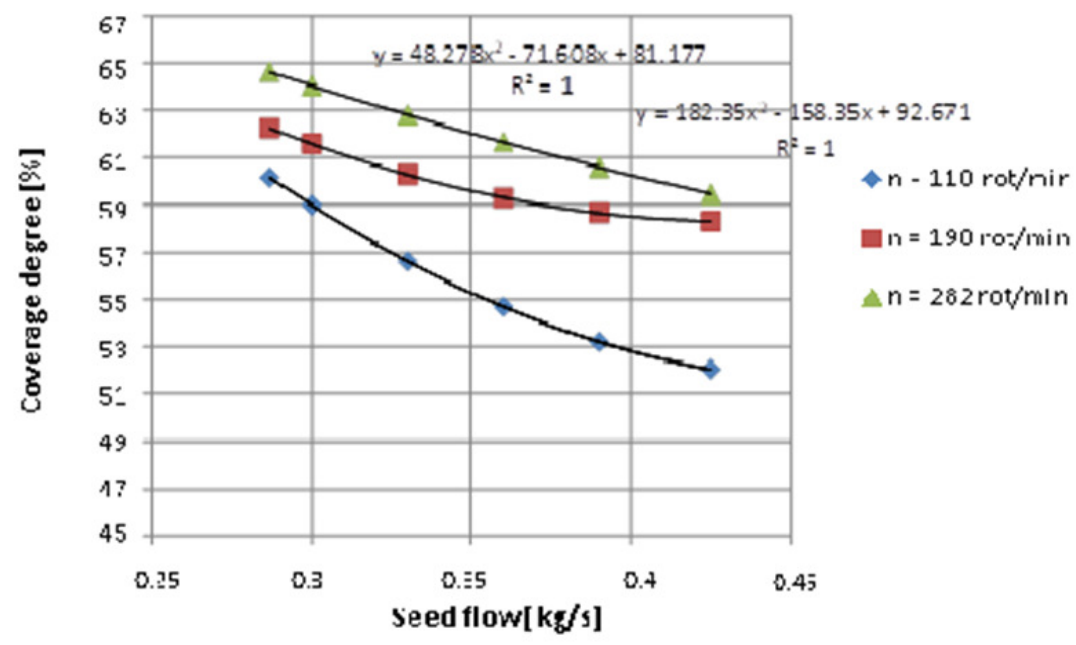

Fig. 8. Variation of the coverage degree according to the seed flow for the liquid flow $Q_{l}=0.65 \mathrm{l} \cdot \mathrm{min}^{-1}$

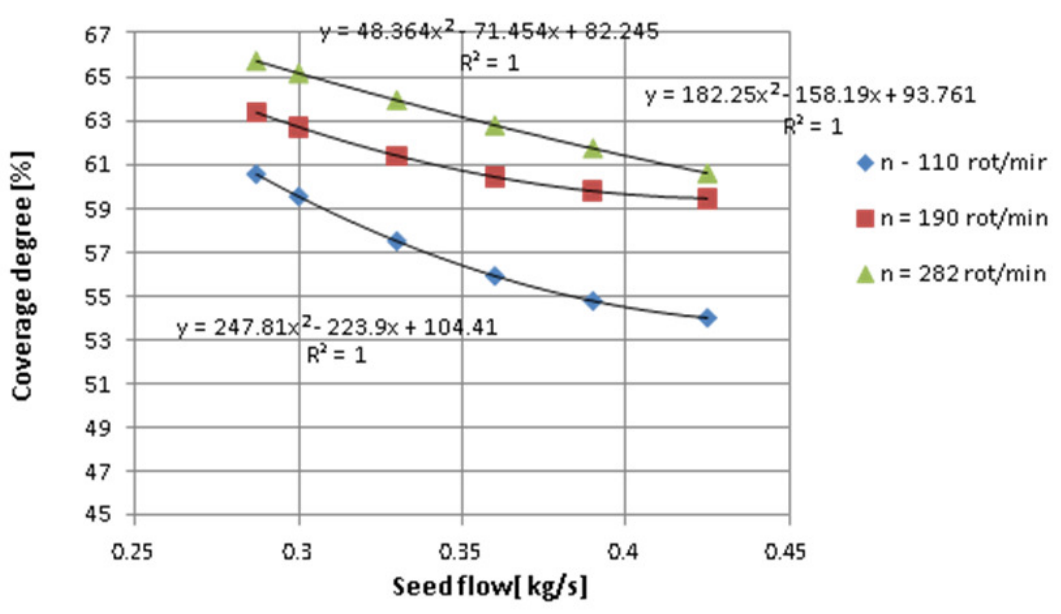

Fig. 9. Variation of the coverage degree according to the seed flow for the liquid flow $Q_{l}=1.21 \cdot \mathrm{min}^{-1}$

\section{Conclusions}

1. Usually whole factor programs contain a large number of experiences compared to the number of coefficients needed to be estimated. It is possible to resort to the fractionation of the program so 
that it does not contain a large number of experiences in excess of the number of coefficients to be estimated with very good results.

2. The large number of determinations made showed once again the importance of each parameter in part and their interdependence. A good adjustment of the equipment influences the coverage degree intermediate and recommends the optimum assurance of all the elements of the equipment component.

3. It is found that with the decrease of the seed flow the coverage degree increases, the best values being obtained at the speed of $282 \mathrm{rpm}$ of the helical conveyor. The degree of final coverage is significantly influenced by the speed of the helical conveyor and by the seed flow, the influence of the drum speed being insignificant in the studied interval (2000-3000 rpm).

\section{Acknowledgement}

This work was supported by a grant of the Romanian Research and Innovation Ministry, through Programme 1 - Development of the national research-development system, subprogramme 1.2 Institutional performance - Projects for financing excellence in RDI, contract No. 16 PFE.

\section{References}

[1] Taylor A.G., Allen P.S., Bennett M.A., Bradford K.J., Burris J.S., Misra M.K. Seed enhancements. Seed Sci. Res. 1998, 8, pp. 245-256.

[2] Daryanto S., Fu B., Wang L., Jacinthe P.A., Zhao W. Quantitative synthesis on the ecosystem services of cover crops. Earth-Sci. Rev. 2018, 185, pp. 357-373.

[3] McKenna P., Cannon N., Conway J., Dooley J., Davies W.P. Red clover (Trifolium pratense) in conservation agriculture: A compelling case for increased adoption. Int. J. Agric. Sustain. 2018, 16, pp. 342-366.

[4] Hutmacher B., Keeley M., Marsh B., Rothrock C. Seed Fungicide Treatment Trials-Update and Data Summary, University of California Cooperative Extension: Davis, CA, USA, 2005.

[5] Schmitt A., Koch E., Stephan D., Kromphardt C., Jahn M., Krauthausen H.J. Evaluation of nonchemical seed treatment methods for the control of Phomavalerianellaeon lamb's lettuce seeds. J. Plant Dis. Prot. 2009, 116, pp. 200-207.

[6] Gerhardson B. Biological substitutes for pesticides. Trends Biotechnol. 2002, 20, pp. 338-343.

[7] Knowles A. Recent development of safer formulations of agrochemicals. J. Environ. 2008, 28, pp. 35-44.

[8] Taylor A.G., Allen P.S., Bennett M.A., Bradford K.J., Burris J.S., Misra M.K. Seed enhancements. Seed Sci. Res. 1998, 8, pp. 245-256.

[9] Bose B., Kumar M., Singhal R.K., Mondal S. Impact of Seed Priming on the Modulation of Physico-chemical and Molecular Processes During Germination, Growth, and Development of Crops.2018, Advances in Seed Priming, pp. 23-40.

[10]Zaica A., Visan A., Zaica A., Olan M., Bunduchi G. Coating process of corn grains using treatment machine with brush screw conveyor, Engineering for Rural Development, 2224.05.2019 Jelgava, pp. 233-238.

[11]Păunescu I., David L., Bazele cercetării experimentale a sistemelor biotehnice, Editura Printech, 1999.

[12] Directivele Comisiei Uniuni Europene2010/21/EU din 12 Martie 2010, Anexa I pentru a coincide cu directiva 91/414/EEC cerinte privind clothianidin, thiamethoxam, fipronil and imidacloprid.

[13] Metodologii de referința ESA 'Impactul prafurilor de tratat semințe si a particulelor abrazive, parametru de calitate a semințelor tratate', lucrare publicata pe situl ESA website (http://www.euroseeds.org/codes/esta-european-seed-treatment-assurance)

[14] ISTA International Seed Testing Standards (sampling). 